\section{Comparison of Approaches to Spontaneous Breathing Trial for Extubation: Is PAV + Better Than Other Methods?}

\section{To the Editor:}

We have read with interest the RESPIRATORY CARE article entitled "Comparison of proportional assist ventilation plus, T-tube ventilation, and pressure support ventilation as spontaneous breathing trials for extubation: a randomized study" by Teixeira et al. ${ }^{1}$

A spontaneous breathing trial (SBT) is aimed at assessing the readiness for liberation from mechanical ventilation. The 3 usual approaches to an SBT are T-tube, low level of CPAP ( $\left.5 \mathrm{~cm} \mathrm{H}_{2} \mathrm{O}\right)$, and pressure support ventilation $\left(5-8 \mathrm{~cm} \mathrm{H}_{2} \mathrm{O}\right)$, usually performed for a minimum of $30 \mathrm{~min}$ to a maximum of $120 \mathrm{~min}$. A tolerance of the SBT for this duration should prompt assessment for extubation. The SBT trial is better in assessing readiness for extubation than dependency on weaning parameters. ${ }^{2}$ Teixeira et $\mathrm{al}^{1}$ have examined proportional assist ventilation plus $(\mathrm{PAV}+)$ as a new approach for the SBT and aimed to assess the applicability, safety, and efficacy.

The results improve our understanding of the mode PAV+ and the impact of ICU stay on extubation outcome. However, we see certain important issues related to the methods and results of the study.

First, with respect to the methodology, we believe that instead of simple draw and non-blinded study, the investigators could have used a block-randomized and blinded study to obtain an equal number of subjects across the intervention. This would have avoided the high number of subjects undergoing T-tube trial. We question the predictive value of the cuff leak test in predicting upper airway edema. ${ }^{3-5}$ Routine usage may pose a risk of development of ventilatorassociated pneumonia. ${ }^{6}$

Second, with respect to the results section, in Table 1, the reason for admission could have been represented in 2 categories, namely neurological and non-neurological causes. This would give a subject representation of $60 \%$ non-neurological cases and $40 \%$ neurological cases. If the interventions were classified according to this category, the results would show a greater preference for the T-tube trial by the clinician for neurological cases and an equal preference for T-tube and pressure support ventilation for non-neurological cases. The need for noninvasive ventilation was reported as $22.5 \%$, and the comorbidities (COPD) represented $22.5 \%$, so we would like to know whether all COPD subjects required noninvasive ventilation postextubation. It is interesting to note that despite the Glasgow coma score pre- and postextubation being $>10,15 \%$ of subjects failed extubation; this further proves the observation made by Koh et al. ${ }^{7}$ The reported extubation failure is $15 \%$, which is less than the highest rate for re-intubation reported by Esteban et al, which is $47 \% .^{8}$

Although the authors mentioned sensitivity and specificity of PAV + (97.6 and 66.6\%, respectively) in the abstract of the paper, inclusion of complete data (T-tube, pressure support ventilation, and $\mathrm{PAV}+$ ) mentioning the sensitivity and specificity along the receiver operating characteristic curve representation in the paper would have been ideal. In Table 2, it is interesting to note that, when compared with other groups, the requirement of a tracheostomy among subjects who underwent T-tube trial was much less. Does this mean that the sensitivity and specificity of the T-tube trial in predicting extubation was better than that of pressure support ventilation and $\mathrm{PAV}+$ ? Some of the results in Tables 1 and 2 could have been represented in median and interquartile range.

In Table 3, the time spent in the first SBT reported for the T-tube trial was $35.3 \pm 7.5 \mathrm{~min}$; does this mean that there were subjects who did not receive a minimum of 30 min SBT? Since no complications were reported by the authors, is it reasonable to conclude that $\mathrm{PAV}+$ can be utilized for an SBT even in patients with neurological injury. We support the idea proposed by Kacmarek et $\mathrm{al}^{9}$ that the mode of ventilation applied once the patient begins to trigger inspiration has an effect on time to extubation.

Carol Elizabeth Mathews Department of Respiratory Therapy School of Allied Health Sciences, Manipal University

Manipal, Karnataka, India

Asha Kamath PhD

Department of Community Medicine Kasturba Medical College, Manipal University Manipal, Karnataka, India
Ramesh Unnikrishnan MSc RRT Department of Respiratory Therapy School of Allied Health Sciences, Manipal University Manipal, Karnataka, India

The authors have disclosed no conflicts of interest.

DOI: $10.4187 /$ respcare. 04824

\section{REFERENCES}

1. Teixeira SN, Osaku EF, Costa CR, Toccolini BF, Costa NL, Cândia MF, et al. Comparison of proportional assist ventilation plus, T-tube ventilation, and pressure support ventilation as spontaneous breathing trials for extubation: a randomized study. Respir Care 2015;60(11):1527-1535.

2. Tanios MA, Nevins ML, Hendra KP, Cardinal P, Allan JE, Naumova EN, Epstein SKA. Randomized, controlled trial of the role of weaning predictors in clinical decision making. Crit Care Med 2006;34(10): 2530-2535.

3. Ochoa ME, Marín Mdel C, Frutos-Vivar F, Gordo F, Latour-Pérez J, Calvo E, Esteban A. Cuff-leak test for the diagnosis of upper airway obstruction in adults: a systematic review and meta-analysis. Intensive Care Med. 2009;35(7):1171-1179.

4. Shin SH, Heath K, Reed S, Collins J, Weireter LJ, Britt LD. The cuff leak test is not predictive of successful extubation. Am Surg 2008;74(12):1182-1185.

5. Patel AB, Ani C, Feeney C. Cuff leak test and laryngeal survey for predicting post-extubation stridor. Indian J Anaesth 2015;59(2): 96-102.

6. Mietto C, Pinciroli R, Patel N, Berra L. Ventilator associated pneumonia: evolving definitions and preventive strategies. Respir Care 2013;58(6):990-1007.

7. Koh WY, Lew TW, Chin NM, Wong MF. Tracheostomy in a neuro-intensive care setting: indications and timing. Anaesth Intensive Care 1997;25(4):365-368.

8. Esteban A, Frutos-Vivar F, Ferguson ND, Arabi Y, Apezteguía C, González M, Epstein SK, Hill NS, Nava S, Soares MA, D’Empaire G, Alía I, Anzueto A. Noninvasive positive-pressure ventilation for respiratory failure after extubation. $\mathrm{N}$ Engl J Med 2004;350(24):2452-2460.

9. Kacmarek RM, Villar J, Blanch L. Why use anything but a standard spontaneous breathing trial to determine readiness for ventilator discontinuation? Respir Care 2015;60(11): 1705-1707. 